\title{
Reactor Thermal-Hydraulic
} FY1986 Status Report for the Multimegawatt Space Nuclear Power Program

Principal Investigators

W. J. Krotink

Z. I. Antoniak

October 1996

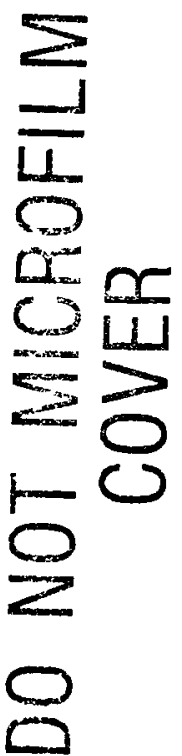

Prepared for the U.S. Department of Energy under Contract DE-ACO6-76RLO 1830

Pacific Northwest Laboratory

Operated for the U.S. Department of Enersy. by Dattelle Memorial Instifute

\section{-Ballelle}




\section{DISCLAIMER}

This report was prepared as an account of work sponsored by an agency of the United States Government. Neither the United States Government nor any agency Thereof, nor any of their employees, makes any warranty, express or implied, or assumes any legal liability or responsibility for the accuracy, completeness, or usefulness of any information, apparatus, product, or process disclosed, or represents that its use would not infringe privately owned rights. Reference herein to any specific commercial product, process, or service by trade name, trademark, manufacturer, or otherwise does not necessarily constitute or imply its endorsement, recommendation, or favoring by the United States Government or any agency thereof. The views and opinions of authors expressed herein do not necessarily state or reflect those of the United States Government or any agency thereof. 


\section{DISCLAIMER}

Portions of this document may be illegible in electronic image products. Images are produced from the best available original document. 


\title{
Dascuane
}

This report was prepared as an sccount of work sponeared by an nesocy of the

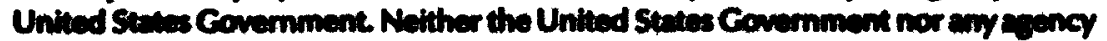

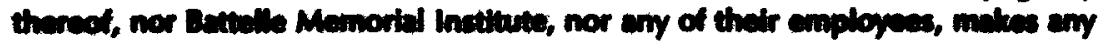

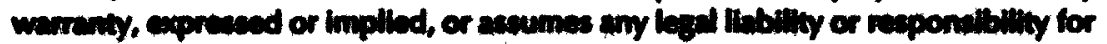

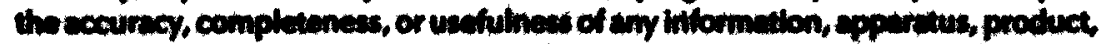

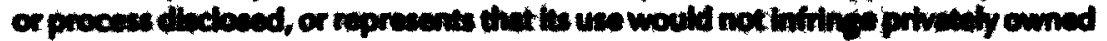

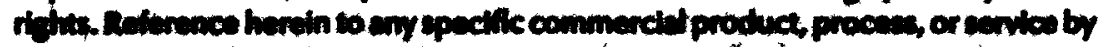

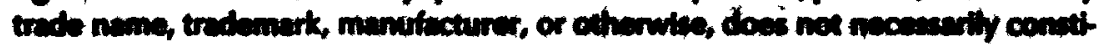

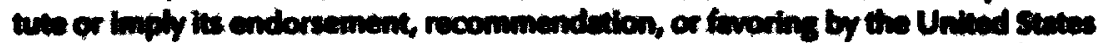

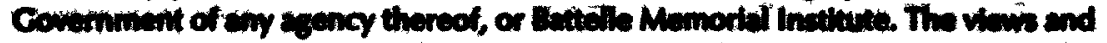

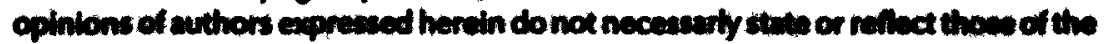

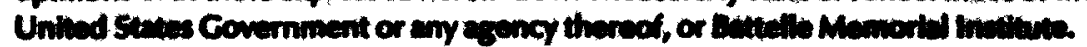

\author{
PACIFIC NORTHWEST LABORATORY \\ operated by \\ BATTELE \\ for the \\ UNITED STATES DEPARTMENT OF ENERGY \\ under Contract DE-ACOG-76RLO 1830
}

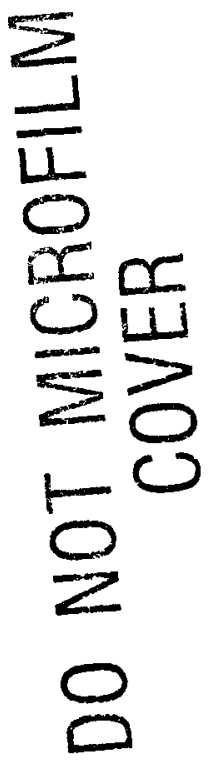

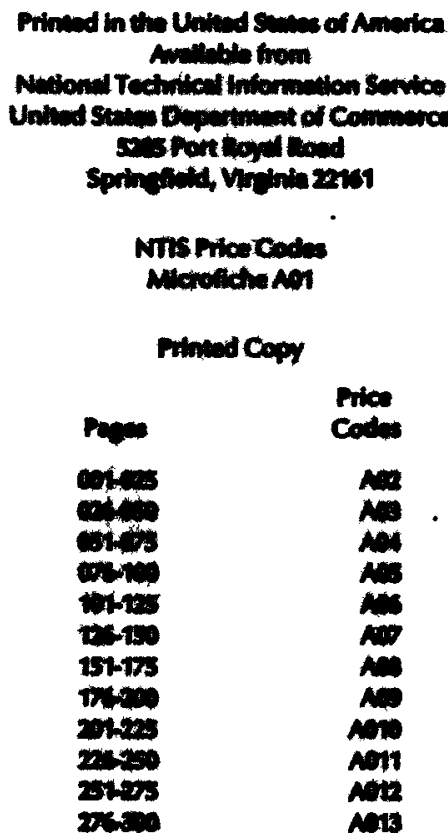




\section{DISCLAIMER}

This report was prepared as an account of work sponsored by an agency of the United States Government. Neither the United States Government nor any agency thereof, nor any of their employees, makes any warranty, express or implied, or assumes any legal liability or responsibility for the accuracy, completeness, or usefulness of any information, apparatus, product, or process disclosed, or represents that its use would not infringe privately owned rights. Reference herein to any specific commercial product, process, or service by trade name, trademark, manufacturer, or otherwise does not necessarily constitute or imply its endorsement, recommendation, or favoring by the United States Government or any agency thereof. The views and opinions of authors expressed herein do not necessarily state or reflect those of the United States Government or any agency thereof.

REACTOR THERMAL-HYDRAULIC

FY1986 STATUS REPORT FOR

THE MULTIMEGAWATT SPACE

NUCLEAR POWER PROGRAM

\section{Principal Investigators}

W. J. Krotiuk

Z. I. Antoniak

October 1986

Prepared for

the U.S. Department of Energy

under Contract DE-AC06-76RLO 1830

Pacific Northwest Laboratory

Richland, Washington 99352

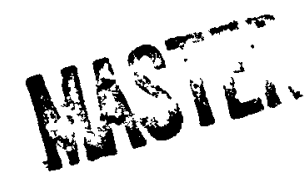

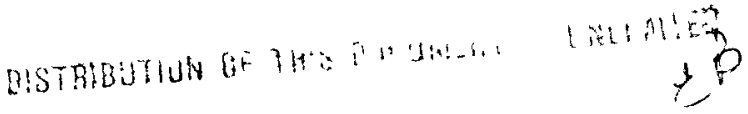




\section{SUMMARY}

A number of reactor designs have been proposed by the DOE national laboratories and by industry as part of the MMW Space Nuclear Power Program. The reactor types proposed can generally be categorized into three cooling types: gas cooled reactors, alkali metal reactors, and thermionic fuel reactors. The ability to assess and analyze the thermal-hydraulic performance of the various reactor types is extremely important to the final selection and design development. The lack of verified codes to adequately predict the thermal-hydraulic operating conditions for both steady-state or transient conditions could lead to dire consequences. Specifically, if parameters such as heat transfer coefficient, pressure drop, or critical heat flux cannot be adequately calculated from the correlations employed, their use could result in an overly conservative design which possesses unnecessary weight, or decrease the safety of a design which in the worst case would lead to fuel failure and melting. A separate detailed Thermal-Hydraulic Assessment Report has been written which addresses the Pacific Northwest Laboratory's (PNL's) FY1986 activities and analysis capabilities in its role as lead laboratory for Reactor Thermal Hydraulics.

PNL's 1986 activities can be divided into three basic areas: code assessment, correlation assessment and experimental activities. The ultimate goal of all these activities is developing computer codes and verifying their use to perform the thermal-hydraulic analysis and design of the reactor core and plenum of the various proposed concepts. To perform this task an assessment must be made of existing computer codes, models, correlations, and microgravity experimental data.

To minimize computer code development time and to maximize use of existing state-of-the-art methods, it was decided to choose existing normal gravity computer codes as base codes from which microgravity computer codes could be developed. An assessment was made of the important relations which would be affected by microgravity conditions and would need to be modified in existing codes. Using this information, a rating system was developed to choose the base codes. As a result, computer codes have been identified which would 
serve as the basis for development of reactor core and plenum microgravity codes. The selected codes are indicated on Table E.1.

All of the chosen codes will require modifications to their constitutive models, numerical methods and permissable input geometry to enable the analysis of the various MMW reactor concepts in microgravity. The one-phase alkali metal core and plenum codes must be modified to include the calculation of microgravity turbulence, freeze-melt and low velocity heat transfer effects. Modifications must also be introduced to permit the input and calculation of the pressure drop and heat transfer effects of the various proposed core geometries. The gas cooled core and plenum codes must also be modified to address microgravity turbulence and low velocity heat transfer, but will also require modifications to address compressibility, geometrical pressure drop and heat transfer, and possibly particle transport effects. Porous media pressure drop and heat transfer correlations must also be introduced into the gas cooled core codes. The ability to model particle bed and other porous media designs is an important concern that must be addressed for both the

TABLE E.1. Base Codes for Microgravity Application

\begin{tabular}{l|l|l|l}
$\begin{array}{l}\text { One Phase } \\
\text { Alkali Metal }\end{array}$ & $\begin{array}{l}\text { Systems } \\
\text { TRAC-BD1 (a) } \\
\text { (Athena) }\end{array}$ & COBRA-WC & TEMPEST \\
\hline $\begin{array}{l}\text { Two Phase } \\
\text { Alkali Metal }\end{array}$ & $\begin{array}{l}\text { TRAC-BD1 (a) } \\
\text { (Athena) }\end{array}$ & $\begin{array}{l}\text { CAPRICORN } \\
\text { COMMIX-2 Further } \\
\text { COBRA-NC Assessment } \\
\text { THERMIT Required } \\
\text { TRAC-BD1 }\end{array}$ & $\begin{array}{l}\text { COMMIX-2 Further } \\
\text { THERMIT Assessment } \\
\text { TRAC-BD1 Required }\end{array}$ \\
\hline $\begin{array}{l}\text { Gas } \\
\text { Cooled }\end{array}$ & $\begin{array}{l}\text { Subchannel Design } \\
\text { COBRA-SFS }\end{array}$ & $\begin{array}{l}\text { TRAC-BD1 (a) } \\
\text { POROUS Media Bed Design } \\
\text { TEMPEST } \\
\text { (AThena) }\end{array}$ & TEMPEST \\
\hline
\end{tabular}

(a) Alternate backup codes 
whole core porous media design, and the subchannel design which includes the particle bed reactor core. Only after these modifications are introduced and verified can the one-phase computer codes confidently model the microgravity steady-state and transient phenomenon needed to insure an optimal and safe design.

Further assessment is required to finalize the choice of base two-phase alkali metal codes because these calculational methods have not undergone as extensive a normal gravity development and verification effort as the onephase codes. Two-phase codes can also be more strongly affected by the absence of gravity. Thus, basic assessments must be made to determine the most appropriate form of the two-phase alkali-metal conservation equations, the most appropriate numerical method and the critical heat flux, freeze-melt, twophase pressure drop, heat transfer coefficient and flow regime calculational methods. These assessments must be made considering the effects of microgravity to ensure adequate reactor design and safety.

Table E.1 also indicates the choice of a base systems code. This selection was made because significant feedback exists between the reactor core and other system components especially for transients. Versions of the reactor core and systems codes must be combined to obtain meaningful results for many analyses. Additionally, at the start of the project, no program approach existed for the development of a systems code and it became necessary to start the initial research to assure progress later.

The reactor plenum codes will be primarily developed to determine multidimensional flow and temperature distributions in the inlet and outlet plenum of a reactor core. This calculation is necessary to ensure acceptable core flow distributions or to supply design input. The lack of the ability to predict acceptable steady-state and transient core flow distributions could affect safety by resulting in local fuel hot spots and possible fuel failure. These codes are general multidimensional computer codes which could eventually be used for the analyses of other general microgravity flow problems associated with other system components. Fluid turbulence behavior is one of the primary unknowns in microgravity. The main modeling problem for determining plenum 
conditions revolves around the ability to develop and verify microgravity fluid turbulence calculations.

The Thermal-Hydraulic Assessment Report also assesses the adequacy of existing thermal-hydraulic correlations for microgravity calculations. This task required an extensive survey of existing correlations for gas, one-phase, two-phase, and porous media thermal hydraulics. It also included a survey of existing microgravity thermal-hydraulic experimental data. In many areas, especially those relating to one-phase low velocity flow, two-phase alkali metal flow, and turbulence flow conditions, adequate thermal-hydraulic correlations and microgravity experimental data are nonexistent, resulting in the conclusion that methods for ensuring the design of a safe space reactor are currently nonexistent. There is an urgent need for experimental microgravity data. In any case, recommendations for thermal-hydraulic correlations are made in all areas based on the best available correlations even though they are not totally applicable to proposed operating conditions. The required experimental facilities, data and resulting correlations outlined in the Assessment Report could be used by many other technology elements and system components in addition to the reactor core. The experimental results and developed correlations would be applicable to general microgravity thermalhydraulic analysis.

In addition to identifying microgravity analytical deficiencies the lack of adequate alkali metal thermophysical and state properties in appropriate pressures and temperature ranges was also identified. Experimental data is also required in this area to permit a safe, cost effective, weight efficient reactor design.

Volume II of the Thermal-Hydraulic Assessment Report addresses the proposed experiment plan. Experiments are planned on earth and in low gravity test facilities. The proposed test results and facilities could be useful to a number of other elements (Figure E.1). Planned earth based tests include the measurement of thermophysical and state properties of alkali metals, the development of thermal-hydraulic data for one- and two-phase flow and the assessment of techniques for simulating microgravity such as magnetic levitation in alkali metal flow. 
Low gravity. experiments are proposed primarily using drop towers and parabolic aircraft flights. Eventually, one or more confirmatory shuttle flights are also hoped for. The planned low gravity tests would primarily be performed using benign fluids such as water or Freon. Alkali metal tests would also eventually be required to serve as confirmation for developed correlations and models. The alkali metal loop requires a long lead time for construction, and material and equipment procurement. Thus, it is important to start construction of a test loop early in the program to permit the availability of test data when analysis results are required. The Assessment Report also contains the preliminary assessment study for the location and costs of an alkali metal test facility.

Since many other government agencies are interested in performing lowgravity fluid experiments, cooperative agreements are encouraged with NASA laboratories, the Air force and organizations involved with space commercialization activities. Toward this end, joint boiling/condensing low gravity experiments are currently being conducted with Texas A\&M University under the auspices of NASA. These tests will make use of the NASA KC-135 aircraft to obtain low gravity conditions. Additionally, a cooperative agreement is being worked out with NASA Lewis Research Center to permit use of their drop tower facilities.

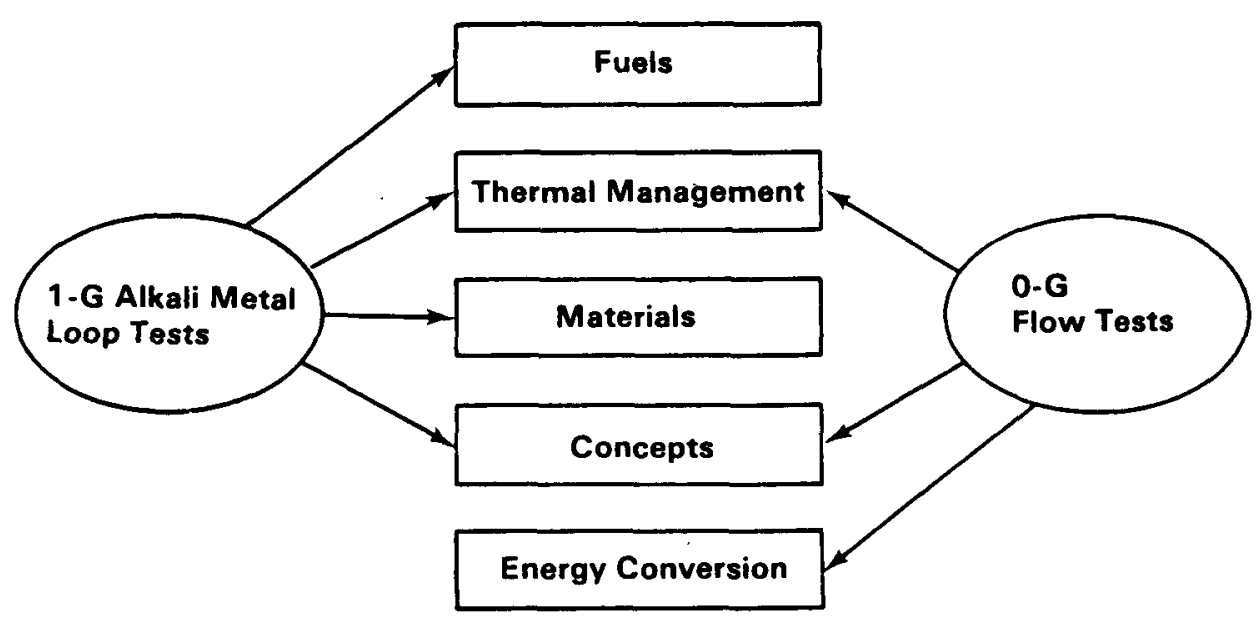

FIGURE E.1. Reactor Thermal-Hydraulic Experimental Interfaces 
BLANK 


\section{CONTENTS}

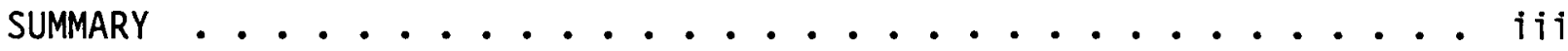

1.0 INTRODUCTION . . . . . . . . . . . . . . . . . . . 1

2.0 TASK DESCRIPTION AND RESULTS . . . . . . . . . . . . . . 2

2.1 REACTOR THERMAL-HYDRAULIC COMPUTER CODE IDENTIFICATION . . . . 2

2.2 CONSTITUTIVE MODEL IDENTIFICATION . . . . . . . . . 2

2.3 EXPERIMENTAL ACTIVITIES ....................... 3

2.4 INPUT DATA AND PARAMETER IDENTIFICATION . . . . . . . . 3

2.5 DRAFT ASSESSMENT REPORT . . . . . . . . . . . . . . 4

3.0 CONCLUSIONS AND RECOMMENDATIONS . . . . . . . . . . 5 


\subsection{INTRODUCTION}

The FY86 Programmatic and Funding Guidance Letter supplied to the DOE Richland Operations Office on March 28, 1986 identified the following key technology issues for the Reactor Thermal-Hydraulic task:

1. Identify the reactor thermal-hydraulic computer codes that exist or need to be developed to serve as a standard set of models that can be used to evaluate the various proposed microgravity MMW reactor concepts.

2. Identify the constitutive relations needed for the analysis of the oneand two-phase microgravity reactor concepts.

3. Identify the experimental data required to validate the computer codes and to develop the constitutive relations needed to analyze the microgravity reactor concepts. Design of the required experiments could also begin.

4. Identify the input data and parameters required for the analysis of the proposed reactor concepts.

5. A draft assessment report addressing the needs of all the laboratory concepts is to be available at the end of FY86. This report is to be updated in FY87 to reflect the needs of the proposed industrial concepts. 


\section{BLANK}




\subsection{TASK DESCRIPTION AND RESULTS}

The important results of the FY86 efforts is included in the Summary. This section will specifically address the key technology elements identified in Section 1.0. PNL is also currently participating in the MMW ThermalHydraulic Working Group, whose activities include all the identified technology issues.

\subsection{REACTOR THERMAL-HYDRAULIC COMPUTER CODE IDENTIFICATION}

As indicated in the Summary, base computer codes applicable to the thermalhydraulic analysis of MMW space reactors have been identified. A comparative rating system was developed to choose the best of approximately 50 codes considered. The final computer codes would be developed by modifying these base codes to perform microgravity core and plenum thermal-hydraulic analyses. Final selection of base codes for two-phase core and plenum analysis is not possible without further assessment because of questions regarding the most appropriate form of the conservation equations and the best numerical procedure for solving two-phase alkali-metal flows. Base codes are currently available for analysis of one-phase alkali-metal and gas-cooled reactor cores. Though these one-phase codes require modifications and have not been verified for microgravity applications, it is felt that these codes would be applicable for the analysis of one-phase forced convection cooling conditions when gravitational effects are not prominent.

\subsection{CONSTITUTIVE MODEL IDENTIFICATION}

Constitutive relations have been identified for use of the thermalhydraulic analysis of gas-cooled and one- and two-phase alkali-metal-cooled reactor concepts. An extensive literature survey was performed to accomplish this task. These recommended relations are the best, most appropriate normalgravity relations which could be applied to reactor design. However, all of these relations are not totally applicable to the design of the MMW reactors 
due to the differences in geometry and operating conditions or due to the presence of microgravity conditions, but they represent the best or only correlations available. Thus, experimental data is required to develop and verify new constitutive relations for MMW microgravity reactor applications.

\subsection{EXPERIMENTAL ACTIVITIES}

The experimental data required to validate the microgravity computer codes and the microgravity constitutive relations are identified in the documentation listed in Section 2.5. As indicated in the Summary, efforts have already begun to perform low-gravity experiments in cooperation with Texas A\&M University. Cooperative agreements are also being worked out with NASA Lewis Research Center to permit use of their drop tower facilities. Additionally, extensive surveys of available low-gravity and two-phase alkalimetal experiments have been completed to determine their applicability to the MMW reactor concepts. The survey results justify the need for experimental thermal-hydraulic data. Deficiencies in the alkali-metal thermophysical and state properties in appropriate pressure and temperature ranges have been identified.

Princeton University has completed a study to assess the feasibility of using magnetic levitation to approximate low-gravity conditions for performing thermal-hydraulic experiments of one- and two-phase alkali metals. Initial assessments of employing ultrasonic techniques for the measurement of void fraction in a fluid flow has also been completed. Finally, HEDL and ETEC have completed assessments of the cost and schedule requirements necessary to construct two-phase alkali-metal experimental loops.

\subsection{INPUT DATA AND PARAMETER IDENTIFICATION}

Reactor concept information has been requested from all laboratory proposed concepts. Copies of received core concept descriptions have been forwarded to SNL for use in the independent assessment task. Correlation recommendations 
have been transmitted to SNL, BNL, and ORNL. PNL comments were also supplied to SNL regarding their Concept Definition Summary Data Sheets.

\subsection{DRAFT ASSESSMENT REPORT}

All of the FY86 efforts regarding computer code assessment, constitutive relation assessment, and experimental activities are reported in detail in the following documents:

Thermal-Hydraulic Assessment Report for the Multimegawatt Space Nuclear Reactor Program (Draft), Volumes I and II, Pacific Northwest Laboratory, September 1986.

Two-Phase Alkali-Metal Experiments in Reduced Gravity, PNL-5906, Pacific Northwest Laboratory, June 1986. 
BLANK 


\subsection{CONCLUSIONS AND RECOMMENDATIONS}

Correlations for important thermal-hydraulic parameters, especially for two-phase alkali-metal and low-velocity one-phase fluid flow, are needed to adequately design a space reactor. Available two-phase alkali-metal critical heat flux, heat transfer coefficient, and pressure drop correlations at the proposed design pressures are nonexistent for normal earth-gravity correlations. At microgravity conditions, no correlations are available. Low-velocity heat transfer coefficient correlations for a one-phase fluid in microgravity are nonexistent. Turbulence models for a one-phase fluid in normal gravity are not applicable to microgravity conditions. Thermophysical and state properties for alkali metals at the proposed operating conditions are not available.

The lack of the indicated information hinders the analysis and design of the MMW space reactors. Base computer codes have been selected for MMW reactor applications, but the codes and models must be modified and verified. Experimental data is required to support the constitutive model and computer code development effort. Long lead times are required to build experimental facilities, conduct tests, and accumulate test data. Experimental activities must be started now to ensure the availability of test data for correlation and code verification. The cutback of thermal-hydraulic funding affects the availability of the test data at the required time. Thus the computer codes made available would contain unverified thermal-hydraulic models, which would result in questionable design and safety analysis results. Unverified analytically developed data could result in an overweight, overconservative design or, in the worst case, an unsafe design which would be subject to failure.

As a minimum, the following analytical and experimental activities are recommended for FY87. Funding cutbacks will affect the performance of these tasks:

\section{Analytical Activities}

- support distribution of gas-cooled and one-phase alkali-metal core codes 
- modify base gas-cooled core code to permit modeling of porous medium core

- modify base gas-cooled core code to permit modeling of particle bed core

- complete work to select base two-phase alkali-metal core code

- start upgrade of two-phase alkali-metal core code for microgravity and reactor design conditions.

2. Experimental Activities

- send representative to International Boiling Liquid Metal Working Group Meeting in Ispra, Italy

- continue KC-135 water boiling/condensing experiments with Texas A\&M

- start drop tower tests

- start thermophysical and state alkali-metal property experiments

- start small alkali-metal test loop construction.

As in FY86, reactor plenum code development activities are almost ignored. The above indicated activities are perceived as the bare activities necessary to support the Reactor Thermal-Hydraulic task and meet the 1991 downselection. Currently envisioned thermal-hydraulic funding would not be able to support even this minimum activity level. With the preliminary funding indicated for FY87, only the analytical activities can be emphasized. The first three items, and part of the fourth item of the analytical task, and the first item and parts of the second item of the experimental activities would be given precedence. Thus the preliminary indicated funding level seriously impacts the Reactor Thermal-Hydraulic schedules and deliverables indicated in the FY86 Project Management Plan and can affect timely support for the MMW Space Reactor Program in subsequent years. 


\section{$\underline{\text { DISTRIBUTION }}$}

No. of

Copies

\section{OFFSITE}

30 DOE Technical Information Center

S. A. Bassett

W. J. Schafer Association

1901 N. Fort Myer Drive

Arlington, VA 22209

C. R. Bell

Los Alamos National Laboratory

PO Box 1663

Los Alamos, NM 87545

D. R. Bennett

Department of Energy (LANL)

NE/521 Germantown

Washington, D.C. 20545

F. R. Best

Nuclear Engineering Department

Texas A\&M University

College Station, TX 77843

S. K. Bhattacharyya

Argonne National Laboratory

9700 S. Cass Bldg. 207

Argonne, IL 60439

R. J. Bohl

Los Alamos National Laboratory

PO Box 1663

Los Alamos, NM 87545

R. H. Cooper

Oak Ridge National Laboratory

PO Box X

Oak Ridge, TN 37831

Louis 0. Cropp

Sandia National Laboratory

Box 5800

Albuquerque, NM 87185
No. of

Copies

\begin{abstract}
P. J. Dirkmaat
Department of Energy

Idaho Operations office

785 DOE Place

Idaho Falls, ID 83402
\end{abstract}

A. E. Duckler

University of Houston

Department of Chemical Engineering 4800 Calhoun

Houston, TX 77004

B. B. Gillies

ETEC/Rockwell International

PO Box 1449

Canoga Park, CA 91304

J. K. Hartman

1333 Broadway Ave

Oakland, CA 94612

E. E. Hoffman

Department of Energy

Oak Ridge Operations Office

PO Box E

Oak Ridge, TN 38730

H. W. Hoffman

Department of Energy

Oak Ridge Operations Office

PO Box X

Oak Ridge, TN 38730

R. L. Holton

Department of Energy

Albuquerque Operations office

PO Box 5400

Albuquerque, NM 87115

J. L. Hooper

Department of Energy

Chicago Operations Office

9800 S. Cass Avenue

Argonne, IL 60439 
No. of

Copies

S. V. Jackson

Los Alamos National Laboratory

PO Box 1663 MS F611

Los Alamos, NM 87545

E. U. Khan (3)

Department of Energy

Headquarters

NE/521 Germantown

Washington, D.C. 20545

W. E. Lambert

Department of Energy

SAN Operations office

1333 Broadway

Oakland, CA 94612

Major R. Lenard

SDI Office/KE

The Pentagon/2E 261

Washington, D.C. 20301

H. Ludewig

Brookhaven National Laboratory

Upton, Long Island, NY 11973

E. T. Mahefkey

AFWAL/POOS-3

Wright-Patterson AFB,

$\mathrm{OH}$ 4533-6563

P. Materna

Princeton University

PO Box 451

Princeton, NJ 08544

J. S. Martinelli

Multimegawatt Space Reactor

Program

Idaho National Engineering Laboratory

PO Box 1625

Idaho Falls, ID 83415

M. A. Merrigan

Los Alamos National Laboratory

PO Box 1663

Los Alamos, NM 87544
No. of

Copies

H. Merte, Jr.

University of Michigan

Department of Mechanical

Engineering and Applied Mechanics 2250 G. G. Brown

Ann Arbor, MI 48109-2125

N. R. Ortiz

Sandia National Laboratory

PO Box 5800

Albuquerque, NM 87185

R. Parrish

Code EC2

NASA Johnson Space Center

Building 7A Room 122

Houston, TX 77058

K. L. Peddicord

Department of Nuclear Engineering

Texas A\&M University

College Station, TX 77843

J. R. Powell

Brookhaven National Laboratory Upton, NY 11973

R. E. Rice (15)

Multimegawatt Space Reactor Program

Idaho National Engineering Laboratory

PO Box 1625

Idaho Falls, ID 83415

D. S. Rowe

14400 Bellevue-Redmond Road

Suite 208

Bellevue, WA 98007

J. A. Salzman

NASA Lewis Research Center

21000 Brookpark Road

Cleveland, $\mathrm{OH} 44135$ 
No. of

Copies

A. Schor

Massachussetts Institute of Technology

Department of Nuclear Engineering

Room 24-215

Cambridge, MA 02139

L. K. Slimak

AFRPL/DYS/STOP 24

Air Force Rocket Propulsion Laboratory

Edwards AFB, CA 93523

R. J. Sovie

NASA Lewis Research Center

21000 Brookpark Road

Cleveland, $\mathrm{OH} 44135$

G. Stapher

Jet Propulsion Laboratory

4800 Oak Grove Drive

Pasadena, CA 91109

F. V. Thome

Sandia National Laboratory

PO Box 5800

Albuquerque, NM 87185

M. J. Thurgood

Numerical Applications, Inc. PO Box 1409

825 Goethals Drive

Suite $A$

Richland, WA 99352

V. Truscello

Jet Propulsion Laboratory

4800 Oak Grove Drive

Pasadena, CA 91109

R. L. Verga

SDI office/SLKT

The Pentagon Building

Washington, D.C. 20301

R. W. Vernon

NASA Lewis Research Center

21000 Brookpark Road

Cleveland, $\mathrm{OH} \quad 44135$
No. of

Copies
E. J. Wahlquist

Department of Energy

Headquarters

NE/521 Germantown

Washington, D.C. 20545

V. Walker

EBASCO Services, Inc.

Applied Physics Department

2 World Trade Center

New York, NY 10048 C. E. Walter

Lawrence Livermore National Laboratory

PO Box 808

Livermore, CA 94550

R. L. Wiley

SDI Office/SLKT

The Pentagon

1717 H. St., N.W.

Washington, D.C. 20301

H. Zweig

ETEC/Rockwell International

PO Box 1449

Canoga Park, CA 91304

R. Parrish

Code EC2

NASA Johnson Space Center

Building 7A, Room 122

Houston, TX 77058

R. D. Hahn

U.S. Department of Energy

DP-22.2 Germantown

Washington, D.C. 20545

C. E. Walter

Lawrence Livermore National Laboratory

PO Box 808

Livermore, CA 94550 
No. of

Copies

ONSITE

4 DOE Richland Operations Office

K. R. Absher (3)

J. J. Sutey

3 Hanford Engineering Development Laboratory

D. S. Dutt

A. Padilla

W. L. Thorne

39 Pacific Northwest Laboratory

Z. I. Antoniak (5)

J. M. Bates

J. 0. Barner

D. B. Cearlock

T. T. Claudson

E. P. Coomes

J. M. Cuta

M. A. Friesel

W. J. Krotiuk (10)

B. M. Johnson

N. J. Lombardo

D. R. Rector

L. C. Schmid

C. W. Stewart

R. A. Stokes

D. S. Trent

B. J. Webb

C. L. Wheeler

R. D. Widrig

Technical Library (5)

Publishing Coordination (2) 